\title{
Análisis de Perspectivas y Significación de La rosa separada de Pablo Neruda
}

\section{APROXIMACION A LA OBRA POSTUMA}

Los ocho libros póstumos de poesía de Pablo Neruda que han aparecido reiteran de manera definitiva un quehacer poético que avanza en la retrospección, en el rècuento de lo que él mismo llamara sus vidas, "las vidas del poeta". ${ }^{1}$ De igual forma en que había seguido escribiendo las estrofas del largo poema cíclico y autobiográfico que decía ser su obra total, recoge en los últimos años de producción temas y motivos anteriormente utilizados, les vuelve a dar vigencia y los hace suyos en el tono francamente otoñal con que escribe su poesía postrera.

Los versos de 2,000 repiten en cierto modo la advertencia apocalíptica de Fin de mundo, a la vez que reafirman la necesidad de una visión esperanzada.hacia el futuro de la humanidad; Jardín de invierno ahonda en la permanencia del ser en la materia como ese "volver a uno mismo"2 que es irremediable; Libro de las préguntas replantea en sus setenta y cuatro composiciones las interrogantes que, de manera explícita o implícita, viene formulando el poeta desde Estravagario; Elegía recoge la nostalgia dolida de Neruda ante los compañeros que han partido, y también cuestiona la permanencia del que sobrevive "con las máscaras nuevas"; ${ }^{3}$ El corazón amarillo retorna al tono excéntrico y risueño, disparatado por momentos, de muchos versos "estravagáricos" de 1958. El mar y las campanas resume las voces del poeta, repartidas entre tanto tiempo y tanta geografía, mencionando nombres y dedicaciones y presintiendo la muerte inminente de la persona que es Pablo Neruda; la tonalidad-ya levemente melancólica, ya apologética-es evocadora de dos de sus libros de la última

1 Título de las Memorias publicadas en $O$ Cruzeiro Internacional en diez entregas (Río de Janeiro, enero 16-junio $1^{\circ}$ de 1962) y significativo término ya aclarado por la biografía y la crítica (cf. Margarita Aguirre, Las vidas de Pablo Neruda (Santiago: Zig.Zag, 1967) y Emir Rodríguez Monegal (El viajero inmóvil, Buenos Aires: Losada, 1966).

2 “"Estrella”, Jardin de invierno (Buenos Aires: Losada, 1974), p. 104.

3:"XVI", Elegía (Buenos Aires: Losada, 1974). p. 74. 
década: Las manos del día y Geografía infructuosa. Defectos escogidos, obra de reciente publicación que pone broche final a medio siglo de poesía nerudiana, conjuga de nuevo la geografía de América con experiencias íntimas del poeta.

En La rosa separada, primer libro póstumo en orden de aparición, ${ }^{4}$ retoma también el poeta un tema ya utilizado desde Canto general: la visita significativa a Isla de Pascua, cantada con sus estatuas de piedra desde los versos de "El gran océano". ${ }^{5}$ Varios motivos se entrelazan en la armazón del libro, que han sido asimismo claves reiterativas a lo largo de la obra nerudiana: la vuelta o regreso al origen, el hombre mudable frente a la materia pétrea inmutable en su esencia, la conciencia de un tiempo fluido y estático a la vez, las constantes del silencio y la soledad invariables de la naturaleza frenta a la voz temporal del hombre. Todos estos hilos temáticos se entretejen en la estructuración del libro, que está diseñado en una división binaria de poemas que se van desarrollando paralelamente.

\section{ESTRUCTURACION DE "LA ROSA SEPARADA"}

Las veinticuatro composiciones numeradas que integran la obra ${ }^{6}$ presentan una simetría nominal, al tiempo que conceptual, cuando se les considera como partes componentes de dos divisiones mayores: dos series de poemas que corren paralelas a lo largo del libro, pero que se entremezclan en una especie de contrapunto temático. Sólo hay dos títulos: diez poemas se denominan "La isla" (los números III, V, VI, VII, VIII, XII, XVII, XX, XXII y XXIV), y catorce se titulan "Los hombres" (los números I, II, IV, IX, X, XI, XIII, XIV, XV, XVI, XVIII, XIX, XXI y XXIII). ${ }^{7}$ Como puede notarse, no siguen un orden específico, sino que se alternan o agrupan en subseries de dos, tres o cuatro como máximo; pero cada serie mayor de poemas constituye un "sublibro" que representa cada una de las polaridades entre las que oscila el punto de vista del hablante poético: el íntimo o personal y el colectivo. Dichos puntos de vista o perspectivas, están dados principalmente por dos hablantes distinguibles: el "yo" figurado en "La isla" y el "nosotros" representado en "Los hombres"-o sea, la figura ficticia del poeta que habla desde su interioridad personal, y una figura colectiva también ficticia, identificada con el resto de los compañeros del

4 De hecho, el poemario fue publicado por vez primera en vida del poeta por Editions du Fragon (Paris, 1972). La edición más difundida, que manejamos aquí, es la de Losada (Buenos Aires, 1973); hay también una segunda de la misma editorial, conmemorativa del $70^{\circ}$ cumpleaños de Neruda, aparecida el 12 de julio de 1974. Todas las referencias hechas en el texto de este estudio remiten a la edición de 1973 .

5 En los poemas "Rapa Nui", "Los constructores de estatuas (Rapa Nui)" y "La lluvia (Rapa Nui)", que se encuentran en la sección de Canto general citada supra, en Obras completas, $3^{a}$ ed. (Buenos Aires: Losada, 1967), vol. I, pp. 660, 661 y 663.

6 Hay un poema-prefacio, sin número, titulado "Introducción en mi tema" (pp. 9-10).

7 El poema que en Canto general precede a los tres sobre Rapa Nui se titula "Los hombres y las islas" (Obras completas, loc. cit., pp. 659-660). El léxico y la imaginería de algunos de aquellos versos se repiten en $L a$ rosa separada. 
viaje a Rapa Nui. ${ }^{8}$ El punto de contacto entre las dos series se logra por la parcial interpolación del "yo" en los textos poemáticos enunciados en plural, y por la secundaria inclusión del "nosotros" en los poemas de título singular.

Así, la lectura de La rosa separada es cuádruple en sus posibilidades. La primera, en el orden lineal total, de principio a fin; éste sería el orden "normal". La segunda y la tercera, siguiendo la ordenación titular de las dos series (poema introductorio, "Los hombres", "La isla", o poema introductorio, "La isla", "Los hombres"); serían éstas lecturas "secuenciales". Por último, una lectura que tomara en cuienta la gradación de la perspectiva; el orden estaría dado por el progresivo acercamiento del hablante a su propia visión personal, dada en el "yo", hasta culminar con la identificación "isla" = objeto amado. Tal lectura se realizaría como sigue: "Los hombres" I, II, IV, IX, XI, XIII, XIV, XV, XVI, XIX - "Los hombres" XVIII y XXI - "La isla" III, V, VI, VII, VIII, XII, XVII, XX, XXIV y XXII. Los poemas en posición intermedia, como veremos más adelante, funcionan a manera de puente o transición entre las series, ya que están conceptualizados desde la intimidad lírica prevalente en " La isla".

La composición que prologa el libro, sin número, y titulada "Introducción en mi tema", funciona como prefacio, resume el tema central de la obra y sintetiza el motivo del regreso al origen, en el cual s' fundan-desde un ángulo temático-los niveles de significación de $L a$ rosa separada.

A la Isla de Pascua y las presencias

salgo, saciado de puertas y de calles,

a buscar algo que allí no perdí.

El mes de Enero, seco,

se parece a una espiga:

cuelga de Chile su luz amarilla

hasta que el mar lo borra

y yo salgo otra vez, a regresar.

Estatuas que la noche construyó

y desgranó en un círculo cerrado

para que no las viera sino el mar.

(Viajé a recuperarlas, a erigirlas

en mi domicilio desaparecido.)

$\mathrm{Y}$ aquí rodeado de presencias grises,

de blancura espacial, de movimiento

8 La calificación de "ficticia" está justificada y explicada cunado partimos de la premisa de que, como en toda obra de imaginación, la figura representada no corresponde a la personalidad real del autor. De los diversos tratamientos de este problema, ponderemos solamente el citado pasaje: "para decidir que el autor mismo dispone de "signos" que diseminaría en su obra es necesario suponer entre la "persona" y su lenguaje una relación signalética que haría del autor un sujeto pleno y del relato la expresión instrumental de esta plenitud: a lo cual no puede resolverse el análisis estructural: quien habla no es quien escribe y quien escribe no es quien existe" (Roland Barthes, en su estudio incluido en Análisis estructural del relato, $2^{\mathrm{a}}$ ed., Buenos Aires: Tiempo Contemporáneo, 1972, pp. 33-34). La observación es válida asimismo aplicada a la lírica. 
azul, agua marina, nubes, piedra, recomienzo las vidas de mi vida.

(pp. 9-10)

Como notamos, el texto se enuncia desde la perspectiva del "yo", del hablante que recomienza en la soledad de la isla. Este es el punto de partida de la bifurcación óptico-conceptual de la obra. La persona o figura del poeta que aquí vemos representada singularmente se integrará después a la colectividad del "nosotros":

aquí estoy, como los otros pesados peregrinos

que en inglés amamantan y levantan las ruinas:

egregios comensales del turismo, iguales a Simbad

y a Cristóbal, sin más descubrimiento

que la cuenta del bar.

Me confieso: matamos

los veleros de cinco palos y carne agusanada, matamos los libros pálidos de marinos menguantes, nos trasladamos en gansos inmensos de aluminio,

(pp. 13-14)

pero ésta es una integración física y materialmente necesaria, impuesta por la obligación de la actualidad histórica. El "yo" íntimo y personalizado lucha por desprenderse de la pluralidad humana, y logra al nivel lírico un verdadero regreso a la raíz del ser, al origen puro, que no comparte con los demás de la colectividad. El distanciamiento se realiza, porque la masa es "ellos" y no "nosotros".
yo, fuera de los otros, me separo
de la isla separada, me voy
envuelto en luz
y si bien pertenezco a los rebaños, al turismo igualitario, a la prole, confieso mi tenaz adherencia al terreno solicitado por la aurora de Oceanía.

(pp. 85-86)

A base de esta tensión dialéctica entre el deber social a la historia de la cual zs parte y la inclinación íntima a una soledad existencial y atemporal, estructura el poeta La rosa separada. Así establece la partitura binaria de un contrapunto coral, en que una serie de poemas refleja la perspectiva pluralizada del hombremasa, superficial y pragmático, frente a la inmutabilidad esencialmente eterna del océano y la piedra (misterios del origen de la vida); mientras que la otra serie comunica el punto de vista del hombre-artista, sensible a una percepción profundizadora del universo como sistema revelador del orden cósmico, y creador de un mensaje que expresa tal visión trascendente. La resolución poética de tal tensión es lo que da sentido y finalidad a la obra.

\section{'COMPOSICION DE LA SERIE "LOS HOMBRES"}

Los catorce textos que componen esta serie, o "sublibro", están enunciados 
principalmente desde una perspectiva colectiva, el "nosotros", expresado tanto por la tercera persona plural como por la tácita igualdad e identificación del "yo" del poeta con la masa humana que visita la Isla de Pascua:

soy igual a la profesora de Colombia, al rotario de Filadelfia, al comerciante de Paysandú que juntó plata para llegar aquí. Llegamos de calles diferentes, de idiomas desiguales, al Silencio.

$$
\text { (p. 17) }
$$

La colectividad está caracterizada, a todo lo largo de la serie, por la modernidad ("nos trasladamos en gansos inmensos de aluminio", vid. supra); por la anonimidad y torpeza ("Somos torpes los transeúntes, nos atropellamos/ de codos,/ de pies, de pantalones, de maletas, / bajamos del tren, del jet, de la nave...", p. 27); por la incapacidad de adaptación a la grandiosa soledad y a la convivencia con las puras raíces del hombre ("Nosotros, los transeúntes, los equivocados de/ estrella,/ naufragariamos en la isla como en una laguna", p. $50)$; por la identificación rutinaria con una vida material sin complicadas inquietudes:

de calle negra con casas de antigüedades

y latas de basura, hermanastros

del número treinta y tres mil cuatrocientos

veintisiete

piso sexto, departamento a, be o jota

frente al almacén "Astorquiza, Williams y

Compañía",

sí, pobre hermano mío que eres yo,

ahora que sabemos que no nos quedaremos

aquí ni condenados, que sabemos

desde hoy, que este esplendor nos queda grande,

la soledad nos aprieta como el traje de un niño

que crece demasiado...

(pp. 53-54)

Es significativo que en este último fragmento citado aparezca un oyente a quien el hablante apostrofa en segunda persona, pero al cual inmediatamente incorpora al "nosotros" tal y como lo hace con su propia figura personalizada en el "yo", haciendo así que lo que predomine en el discurso sea el punto de vista social.

Aparentemente llevando al extremo esta perspectiva, en un poema posterior de la serie, el hablante se adhiere al miedo insensible del viajero común, que quiere escapar ante el misterio de las piedras milenarias y ante las interrogantes suscitadas por la inmensidad de los elementos. 
de aire lúcido, de agua, de pasto duro y puro, huir, huir, huir de la sal, del peligro, . del solitario círculo en el agua desde donde los ojos huecos del mar, las vértebras, los párpados de las estatuas negras mordieron al espantado burgués de las ciudades:

Oh Isla de Pascua, no me atrapes, hay demasiada luz, estás muy lejos, y cuánta piedra y agua: too much for me! Nos vamos! (pp. 73-74)

Notemos que en los cuatro últimos versos, el "yo" no es la figura del poeta, sino más bien la figuración del "burgués de las ciudades" hacia el cual expresa el hablante un cierto desdén por medio de un abrupto cambio de tono (va de un alto lirismo al más cotidiano prosaísmol y aun por la introducción irónica de otro código lingüístico: el inglés de los clásicos turistas simplones.

Más adelante, el poeta-hablante se desasocia de esa colectividad, de ese "Nos vamos!", y vuelve al "yo" solitario que se identifica con la temible dimensión oceánica, que se enfrenta con el silencio y la incógnita de las estatuas y renace empapado de inmensidad. La inmersión en los elementos, aquí como siempre, la devuelve la pureza originaria:

Como algo que sale del agua, algo desnudo, invicto,

párpado de platino, crepitación de sal,

alga, pez tembloroso, espada viva,

yo, fuera de los otros, me separo

de la isla separada, me voy

envuelto en luz

$$
\text { (p. 85) }
$$

El poema XXI de la serie repite tal afirmación, con una enunciación que comunica la subjetividad de un "yo" único, reminiscente e incorporador de vivencias y memorias australes. Este es posiblemente el poema de la serie "Los hombres" que más se aparta de la perspectiva plural y colectiva; ya lo consideramos anteriormente, junto al XVIII, como parte del puente o transición entre las dos series. Su texto sirve, como el del poema introductor de la obra, de exposición ejemplar del motivo del regreso al origen y del viaje retrospectivo por las vidas del poeta.

Yo, de los bosques, de los ferrocarriles en invierno,

yo, conservador de aquel invierno,

del barro

en una calle agobiada, miserable, yo, poeta oscuro, recibí el beso de piedra er. 


\author{
mi frente \\ y se purificaron mis congojas.
}

(p. 97)

Pero se impone la necesidad material de partir de Rapa Nui, de retornar al mundo diario y conocido. $\mathrm{Y}$ entonces se reintegra el hablante poético a la colectividad; el utilitario deber de regresar a la civilización, a la corriente humana y temporal que avanza en la sucesión del cambio, al reducido lugar que le corresponde, le hace confesar que también, como todos, abandona asustado la claridad mítica de los moais de piedra y del silencio azul. El "yo" acepta la imposición social del "nosotros":

allí, en el minúsculo ombligo de los mares,

dejamos olvidada la última pureza,

el espacio, el asombro de aquellas compañías

que levantan su piedra desnuda, su verdad,

sin que nadie se atreva a amarlas, a convivir

con ellas,

y ésa es mi cobardía, aquí doy testimonio:

no me sentí capaz sino de transitorios

edificios, ....

$$
\text { (p. 90) }
$$

El último poema de la serie se reafirma en una colectividad destructora del mundo natural, del equilibrio basado "en la verdad de la piedra y del viento". Si la masa humana descubriera que en la soledad pura se encierran las claves de un vivir armónico, se produciría el final de la isla-la aniquilación del espacio aún no "civilizado": "si todos fueran sabios de golpe y acudiéramos/ a Rapa Nui, la mataríamos," (p. 106).

En el recuento total de la serie "Los hombres", observamos un movimiento pendular, entre las perspectivas del "yo" y del "nosotros", que refleja la composición binaria y fluctuante de la obra. Pero prevalece el plural colectivo, y la figura del poeta solamente irrumpe en la serie cinco veces; las otras tres ocasiones en que aparece el "yo" se deben a un desprendimiento subjetivo, por traspaso e interiorización en otra figura (como "el espantado burgués"), por identificación ("pobre hermano que eres yo") y por depersonalización y sustantivación del pronombre ("el huérfano/ de las multitudes, el yo,/ el triturado...el que quería irse más lejos, siempre," p. 77). Obviamente, hay en la serie "Los hombres" un conflicto planteado por la presencia de la masa humana; ésta, extraña ante la naturaleza en su prístina forma, huye del espacio inescrutable y regresa al orden conocido. No se atreve a enfrentarse con la inmutabilidad pétrea de unos monumentos misteriosos, ni a permanecer en el silencio. El hablante-poeta considera negativamente esta actitud, aunque se incluye en ella por necesidad; pero al mismo tiempo se aparta del resto de la colectividad, y vuelve a un "yo" purificado por el contacto con la armonía natural. 
En una fluctuación de posiciones, exteriorizada en el cambio del "yo" al "nosotros" y viceversa, adopta el hablante poético una conciencia dual frente a las consideraciones centrales de la vida humana (simbólicamente representada en este viaje al "origen"): la libertad personal vis-à-vis el sometimiento a un orden social, el cambio incesante del hombre y la historia dentro de un tiempo "estático" existencial (poéticamente simbolizados en el mar y el viento, movibles es en esencia, frente a la isla y la piedra, aparentemente inmutables). Toda es ta polarización reflejada en la perspectiva oscilante denota la dialéctica en que se funda tanto la serie "Los hombres" como la obra entera: una confrontación del hombre consigo mismo en su dualismo histórico y existencial, en su necesidad de cambio y de permanencia.

\section{COMPOSICION DE LA SERIE "LA ISLA"}

En los diez textos poemáticos que forman esta serie se encuentran dos formas o perspectivas básicas de enunciación: la de un hablante implícito, no representado, y la de un hablante explícito, figurado en el "yo" del poeta o en el "nosotros" colectivo y unificador. La primera consiste en la descripción y caracterización de la Isla de Pascua por medio de un hablante no presente en el plano que se describe o canta. Tal perspectiva no aparece en la serie "Los hombres", donde siempre se puede identificar a una figura dentro del texto, la que funciona como sujeto del enunciado. En "La isla", sin embargo, se halla el punto de vista externo cuatro veces; y en dos de esas ocasiones, la forma enunciada está enmarcada enteramente de tal manera. En el corto poema V leemos:

$$
\begin{aligned}
& \text { Todas las islas del mar las hizo el viento. } \\
& \text { Pero aquí, el coronado, el viento vivo, el } \\
& \text { primero, } \\
& \text { fundó su casa, cerró las alas, vivió: } \\
& \text { desde la mínima Rapa Nui repartió sus } \\
& \text { dominios, } \\
& \text { sopló, inundó, manifestó sus dones } \\
& \text { hacia el Oeste, hacia el Este, hacia el espacio } \\
& \text { unido } \\
& \text { hasta que estableció gérmenes puros, } \\
& \text { hasta que comenzaron las raíces. } \\
& \text { (pp. } 31-32 \text { ) }
\end{aligned}
$$

Este hablante "fantasma" asume rasgos de omnisciencia, indicando siempre el relato de los orígenes de Rapa Nui, las claves del misterio de las estatuas y las constantes referencias a la soledad y al silencio sin nombre que-fuera del plano humano-se comprenden en un contexto cósmico.

Esta obra que labraron las manos del aire, los guantes del cielo, la turbulencia azul, este trabajo hicieron los dedos transparentes: un torso, la erección del Silencio desnudo, la mirada secreta de la piedra, 
la nariz triangular del ave o de la proa y en la estatua el prodigio de un retrato: porque la soledad tiene este rostro, porque el espacio es esta rectitud sin rincones, y la distancia es esta claridad del rectángulo.

$$
\text { (p. 36) }
$$

Dicha perspectiva del hablante implícito, en la que la figura del poeta como elemento del texto se distancia y aparentemente desaparece, ${ }^{9}$ presenta en la serie "La isla" una variación interesante: el lirismo retórico. Al recurrir a la forma interrogante frente al misterio de las masas de piedra en Rapa Nui, el hablante hace uso extenso de la interjección vocativa para dirigir su pregunta a un oyente también implícito, a un receptor-lector que tampoco está presente:

Oh graves dignidades solitarias

quién se atrevió, se atreve

a preguntar, a interrogar

a las estatuas interrogadoras?

(p. 40)

En otros poemas, la interrogación misma funciona sin introducción, insistiendo en discifrar el origen de las estatuas caídas. El hablante sigue dirigiendo su pregunta a alguien que no aparece en el texto o enunciado, y que actúa como implícito receptor del mensaje:

Los rostros derrotados en el centro,

quebrados y caídos, con sus grandes narices

hundidos en la costra calcárea de la isla,

los gigantes indican a quién? a nadie?

(p. 45)

En las más características composiciones de esta serie, aparece la isla o el archipiélago como el "tú" figurado, como el oyente del apóstrofe retórico. Tal recurso marca momentos de alto lirismo en la obra:

Oh Melanesia, espiga poderosa,

islas del viento genital, creadas,

luego multiplicadas por el viento.

De arcilla, bosques, barro, de semen que

volaba

nació el collar salvaje de los mitos:

Polinesia: pimienta verde, esparcida

en el área del mar por los dedos errantes

del dueño de Rapa Nui, el Señor Viento.

(pp. 35-36)

9 Vale recordar que es sólo la figura representada, el hablante explícito, quien desaparece; pues percibimos, "sentimos", la presencia del sujeto implícito en la enunciación por medio de las indicaciones que nos "da". En el caso particular que nos ocupa, el discurso se puede caracterizar como "personal" debido a expresiones como: "pero aqut el coronado...", "esta obra que labraron...", "la distancia es esta claridad...". Los demostrativos y los adverbios locativos, entre otros "shifters" (para emplear la terminología de Jespersen y Jakobson), acercan al lector a ese hablante implícito que enuncia, al "hic et nunc" del tiempo de la escritura. 
El poema XVII de "La isla", que define la imagen titular del libro, es una muestra ejemplar de toda una enunciación lírica "hablada" desde la perspectiva implícita; las metáforas se enlazan en una larga cadena apostrófica en que el hablante, aunque no representado, subjetiviza la materia natural y la convierte en materia poética:

...diente del mar, esposa

del viento de oceanía, oh rosa separada

del tronco del rosal despedazado

que la profundidad convirtió en archipiélago,

oh estrella natural, diadema verde,

sola en tu solitaria dinastía,

inalcanzable aún, evasiva, desierta

como una gota, como una uva, como el mar.

(pp. 81-82)

El lirismo intimista culmina en la obra, sin embargo, a través de la perspectiva de un hablante explícito, la figura del poeta. En actitud similar de apóstrofe, la distancia psíquica entre sujeto y objeto queda reducida a la menor posibilidad con la personificación de la isla en mujer amada de virginal misterio, en el poema XXII de la serie; por lo cual dicho texto, como hemos indicado antes, debería finalizar una lectura realizada en cuanto a la gradación perspectivista exterior $\rightarrow$ interior, colectiva $\rightarrow$ personal, objetiva $\rightarrow$ subjetiva. En imagen unificadora, consistente con la visión básica proyectada en los demás segmentos de la obra, la piedra y el silencio de ese "tú" que es la isla-mujer llevan al hablante a la realización atemporal que buscaba, alejado del "nosotros", r asta que logra ser penetrado por la esencia estática de esa materia pétrea y devie ": un "yo" solo, intimamente ligado al origen mítico representado por Rapa Nui.

Amor, amor, oh separada mía

por tantas veces mar como nieve y distancia,

mínima y misteriosa, rodeada

de eternidad, agradezco

no sólo tu mirada de doncella,

tu blancura escondida, rosa secreta, sino

el resplandor moral de tus estatuas,

la paz abandonada que impusiste en mis manos:

el día detenido en tu garganta.

(pp. 101-102)

Las claves gramaticales del "yo" y del "nosotros", que dan la pauta de la perspectiva en la serie "Los hombres", aparecen en "La isla" con renovado énfasis. La figura del poeta en primera persona es el sujeto te los enunciados que mejor definen la purificación de ese regreso al origen que es el viaje a Isla de Pascua. El peregrinaje anunciado desde el poema $I^{10}$ se completa en el número XII con la autodefinición de la misión personal del poeta: volver a la claridad del espacio elemental, sin tiempo, para recrear la materia mutable de sus vidas

10 "Yo soy el peregrino/de Isla de Pascua, el caballero extraño,..." (p. 13). 
frente a esa permanencia cósmica esencial que sólo él percibe, de entre todos los viajeros.

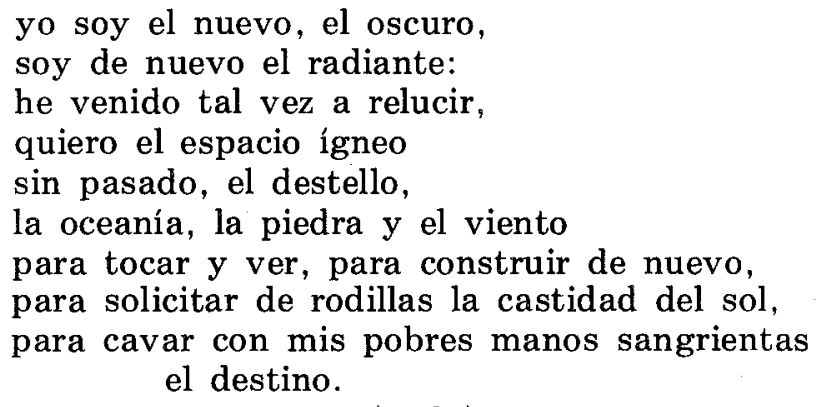

El poema XX de esta serie, tal como lo hace el XXI en "Los hombres", reafirma la perspectiva personal de la figura ficticia del poeta. En él recuenta el hablante algunos lugares geográficos donde entró en contacto con la "impureza" húmeda de la tierra y las vegetaciones, con el más telúrico nivel de la realidad física; de Rapa Nui-agua, piedra, viento-emerge renacido en la pureza de la luz y el espacio infinitos.

De otros lugares (Ceylán, Orinoco, Valdivia)

salí con lianas, con esponjas, con hilos

de la fecundidad, con las enredaderas

y las negras raíces de la humedad terrestre:

de ti, rosa del mar, piedra absoluta, salgo limpio, vertiendo la claridad del viento: revivo azul, metálico, evidente.

(p. 93)

El punto de vista colectivo, el "nosotros", sólo aparece en el primero y en el último poema de la serie: la presentación y la despedida de la isla. La perspectiva plural es la que introduce aquí, como en "Los hombres", el nivel prosaico o "antipoético"; otra vez opone el hablante el materialismo necesario de la vida común a la consideración lírica del "tiempo detenido" en la piedra. Interesante es apuntar en el primer poema la presencia del "tú"-Rapa Nui como oyente figurado - en una especie de invocación clásica con que se prologa la serie:

Antigua Rapa Nui, patria sin voz,

perdónanos a nosotros los parlanchines del mundo:

hemos venido de todas partes a escupir en tu lava,

llegamos llenos de conflictos, de divergencias, de sangre,

de llanto y digestiones, de guerras y duraznos, (p. 21)

El poema último, de la serie y del libro, constituye la despedida del viajero poético. En esta composición está ausente el "yo" y domina el "nosotros", de nuevo con duras referencias a la esterilidad de la vida diaria. El tono enunciativo representa un descenso de la altura lírica; la figura del poeta no está presente en 
el texto, e incluida solamente en la colectividad indiferente e indiferenciada. Adiós, adiós, isla secreta, rosa

de purificación, ombligo de oro:

volvemos unos y otros a las obligaciones

de nuestras enlutadas profesiones y jicios.

Adiós, que el gran océano te guarde

lejos de nuestra estéril aspereza!

$$
\text { (p. 109) }
$$

Este discurso representa un verdadero anticlímax, una inesperada caída desde el punto de vista del "yo", intensamente lírico, a la muda anonimidad del hombremasa que se marcha odiando la soledad: "esconde, isla, las llaves antiguas/bajo los esqueletos/que nos reprocharán hasta que sean polvo" (p. 110). El "nosotros regresaremos" de este texto (al mundo establecido, comercializado, históricamente progresivo y progresista) contrasta diametralmente con el "yo regreso" (al espacio sin límites, sin tiempo, al origen) del poema introductorio. La perspectiva colectiva da un significado semántico enteramente opuesto al regreso; ya no el retorno a la pureza primigenia, sino la vuelta al necesario oficio de vivir diariamente. De ahí que la obra adquiera una delimitación espacial y conceptual como dentro de un marco, compuesto por el motivo final en radical oposición al inicial.

En el recuento total de la serie "La isla", observamos también un movimiento oscilante de perspectivas: entre la de un hablante implícito que canta a Rapa Nui sin ser identificado en el texto, y la de la figura personalizada del poeta, hablando desde su "yo" íntimo y subjetivo. El punto medio de esta especie de perspectivismo está dado por el "nosotros", por esa figura personalizada de la colectividad viajera y humana. En la fuerza lírica y en la frecuencia, domina el hablante poético singular, intimista; en la finalidad sintetizadora del propósito social y humano, prevalece la perspectiva del hablante poético plural, igualador. También hay en la serie "La isla" la dualidad que percibimos en "Los hombres"; tal característica es, a su vez, reflejo de la oposición binaria en que se funda la conceptualización de la obrá: una confrontación de ese "hombre" que "habla", en busca de raices y pureza original, queriendo recuperar el tiempo en una dimensión atemporal, con ese otro "hombre-masa" que también "habla", pero que necesita seguir dentro del tiempo para registrar el progreso de la sociedad y el devenir histórico.

\section{SIGNIFICACION DE "LA ROSA SEPARADA"}

Hemos observado la composición de la obra desde el plano de la perspectiva, o punto de referencia de los distintos hablantes poéticos (figurados o no) que enuncian los textos poemáticos individuales. Así hemos encontrado una división binaria en las enunciaciones, según que los hablantes estén representados (la figura del poeta sola o la figura del poeta dentro del grupo viajero) o que tengan un punto de enunciación no explícito (en los apóstrofes o sentencias líricas, con oyente figurado o no). En frecuencia e intensidad enfática, predominan en cada serie, y en la obra total, las enunciaciones parciales con hablante ficticio figurado 
en un "yo" o en un "nosotros", y la perspectiva en cada nivel estructurador se muestra oscilante entre los polos personal y colectivo (representados a su vez por las figuras gramaticales de primera persona, singular y plural).

Se impone en este punto plantear el problema de La rosa separada como enunciación total. ¿Puede considerarse la obra de este modo? Si estudiamos el discurso lírico total en todas sus posibilidades de lectura y desde las perspectivas oscilantes que se reiteran a cada nivel, percibiremos la obra no como un agregado de textos fragmentarios y divergentes, diferenciados como enunciaciones ficticias de diversas figuras, sino más bien como un todo orgánico. Las veinticinco unidades internas o textos poemáticos parciales están enunciados de manera que cualquiera que sea el orden de la lectura a seguir, cualquiera el ángulo de enfoque temático, las perspectivas básicas de enunciación no varían: el "yo" y el "nosotros" son los mismos hablantes ficticios en las series o sublibros, en el libro completo, en la totalidad de la obra. Se pudiera, a voluntad del lector, reunir y hasta reordenar los textos o discursos parciales en una larga cadena enunciativa que resultaría coherente y completamente inteligible en su lógica interna. La rosa separada, en la mejor tradición nerudiana, no es una colección de poemas; es un solo y largo poema lírico, cuyo sentido y significación son aprehendidos por el lector en función de esa unicidad. Podemos así referirnos a un sujeto de la enunciación total, a un hablante básico que conforma y da unidad a la sucesión de enunciaciones ficticias en los discursos poemáticos parciales, haciendo que éstos funcionen como enunciados integradores de un solo en unciado general.

Ese hablante básico, ya escondido bajo la máscara de la primera persona, ya en el anonimato implícito de la tercera, es quien "habla" y enuncia en la continuidad de las dos series de poemas en la obra; su voluntad estructuradora, por ısí decirlo, es la que dispone el orden y la primacía de las enunciaciones ficticias del "yo" y del "nosotros". Desde su interioridad se visualizan las percepciones de "la isla" y "los hombres" como entidades simbólicas, al nivel único de la soledad y al nivel colectivo de la masa humana. Su perspectiva, implícita en la enunciación total, es la que da unidad a la obra y la destaca como conjunto orgánico; es también la que nos permite percibir, aprehender el sentido de $L a$ rosa separada como un discurso único en que se nos comunica la visión del mundo de quien habla en él; un mundo actualizado poéticamente en su dicotomía existencial e histórica. ${ }^{11}$

11 El problema del punto de vista ha sido extensamente tratado por la crítica contemporánea, aunque con énfasis casi exclusivo en la narrativa. Entre los planteamientos afines más útiles a nuestros propósitos se cuentan los relativos al "discurso personal" formulados por Emile Benveniste en Problèmes de linguistique générale (Paris: Gallimard, 1966), los referentes a la "visión" que ofrece Tzvetan Todorov en su "Poétique", estudio incluido en Qu'est-ce que le structuralisme? (Paris: Editions du Seuil, 1968) y los interesantes comentarios de Jurij M. Lotman en "Point of View in a Text", New Literary History, vol. VI, no. 2 (Winter 1975), pp. 339-352 (dicho artículo, traducido del ruso por L.M. O'Toole, apareció originalmente como el capítulo octavo de la obra Struktura Khudozhestvennogo Teksta, Tartu, 1970). El concepto de "hablante básico" había sido ya discutido en nuestra lengua por Félix Martínex Bonati en La estructura de la obra literaria (Santiago: Editorial Universitaria, 1960), aunque el crítico chileno aplica el término a lo que nosotros preferimos denominar "hablante ficticio no representado", y lo reserva a obras narrativas y similares en el análisis de los modos de decir (vid. nota 4, p. 16). 
Por otra parte, al proponer la obra como lírica, se hace necesario observar que en la medida en que la perspectiva se acerca al "nosotros", se intensifica la función denotativa del lenguaje; el enunciado se llena de referencias a un contexto, o referente, externo - los detalles cotidianos de la vida actual, tomados en su más sencilla acepción, el habla corriente en que se cuentan los pormenores de un viaje aéreo. No así cuando consideramos los enunciados que tienen principalmente al "yo" como sujeto: en ellos el énfasis recae sobre la función ya emotiva, ya connotativa del lenguaje, y el discurso mismo como signo-los significantes de que se compone-pasa claramente a esa dimensión polisémica y compleja que da a la poesía lírica su esencia simbólica. No hay tal ambigüedad o densidad en el lenguaje con que se expresa el sujeto plural "nosotros". ${ }^{12}$ Por esto creemos que la perspectiva básica de enunciación de La rosa separada, mensaje en que la dimensión apelativa y representativa del lenguaje poético pasan a segundo término, se estructura formalmente desde los enunciados en que aparece-como hablante singular, como "yo"-la figura literaria del poeta. Ello da a la obra su eminente carácter lírico, expresando directamente las vivencias de esa realidad aprehendida desde una posición estéticamente singular, sin perjuicio de la relación ficticia de unos viajes y descripciones de turistas enunciados desde un punto de vista colectivo.

La perspectiva plural es el extremo polar necesario, no sólo para servir de lastre al vuelo lírico del "yo" de un hablante-poeta que se confiesa gregario y humanizante en la obra, sino también para situarlo en la ambigüedad históricoexistencial en que se encuentra como miembro de la sociedad. La tensión del conflicto exteriorizado en la perspectiva dialéctica se resuelve de ese modo en el discurso lírico con una síntesis interpretativa del punto de vista dual y oscilante: el hablante básico en La rosa separada es un "yo" que nunca se separa del "nosotros", por deber social, por requisito de su temporalidad esencial. ${ }^{13}$ Así como la Isla de Pascua sobrevive en un simbolismo dinámico y estático a la vez - la doble dimensión del aire y de la piedra-el hablante poético se realiza en una esencialidad binaria que dice de su conciencia como hombre que cambia y como artista que permanece en su obra, que canta así de sus deberes, de sus vidas. De esta manera entronca $L a$ rosa separada con ese largo poema cíclico de Pablo Neruda que seguimos leyendo, y que está lleno aún de perspectivas que descubrir.

University of Arizona, Tucson

ELIANA RIVERO

12 Amplia también es la bibliografía sobre el lenguaje y sus funciones; por razones de espacio, remitimos solamente al texto de Roman Jakobson "Linguistics and Poetics", incluido en Style in Language, ed. by Thomas A. Sebeok (Cambridge, Mass.: MIT, 1960).

13 Nos ha resultado de gran utilidad cotejar estas conclusiones nuestras con las reflexiones que entrega Nelson Osorio sobre la perspectiva del hablante básico que emerge en "Alturas de Macchu Picchu", en un trabajo titulado "El problema del hablante poético en Canto general", aparecido en Simposio Pablo Neruda (Universidad de South Carolina, 1975). 